\title{
In vitro study on radiographic gray levels of biomaterials using two digital image methods
}

\section{Estudo in vitro dos níveis radiográficos de cinza de biomateriais utilizando duas modalidades de imagem digital}

\begin{abstract}
Purpose: To compare the direct and indirect radiographic methods for assessing the gray levels of biomaterials employing the Digora for Windows and the Adobe Photoshop CS2 systems.

Methods: Specimens of biomaterials were made following manusfacturer's instructions and placed on phosphor storage plates (PSP) and on radiographic film for subsequent gray level assessment using the direct and indirect radiographic method, respectively. The radiographic density of each biomaterial was analyzed using Adobe Photoshop CS2 and Digora for Windows software.

Results: The distribution of gray levels found using the direct and indirect methods suggests that higher exposure times are correlated to lower reproducibility rates between groups.

Conclusion: The indirect method is a feasible alternative to the direct method in assessing the radiographic gray levels of biomaterials, insofar as significant reproducibility was observed between groups for the exposure times of 0.2 to 0.5 seconds.
\end{abstract}

Key words: Digital dental radiography; radiographic density; software validation

\section{Resumo}

Objetivo: Comparar os métodos radiográficos direto e indireto para avaliar os níveis de cinza de biomateriais empregando os sistemas Digora for Windows e Adobe Photoshop CS2.

Métodos: corpos de prova confeccionados com biomateriais foram posicionados numa película radiográfica e numa placa de fósforo com protetor para a realização de exposições radiográficas e posterior avaliação dos níveis de cinza por meio dos métodos indireto e direto, respectivamente. A densidade radiográfica de cada biomaterial foi analisada usando-se os sistemas Adobe Photoshop CS2 e Digora for Windows.

Resultados: A distribuição de níveis de cinza observada por meio dos métodos direto e indireto sugeriu uma menor reprodutibilidade entre grupos quanto maior o tempo de exposição.

Conclusão: $\bigcirc$ método indireto constitui uma alternativa viável ao método direto para avaliar os níveis radiográficos de cinza de biomateriais na medida em que foi observada uma reprodutibilidade significativa entre grupos nos tempos de exposição de 0,2 a 0,5 segundos. Palavras-chave: Radiografia dentária digital; densidade radiográfica; validação de software

\author{
Newton Fernando Sobreira Nóbrega a \\ Andrea Puchnick ${ }^{a}$ \\ Leandro Kfouri Martins Cerqueira ${ }^{\circ}$ \\ Claudio Costa ${ }^{b}$ \\ Sérgio Ajzen “
}

\begin{abstract}
Department of Image Diagnostics, São Paulo School of Medicine, Federal University of São Paulo (UNIFESP), São Paulo, SP, Brazil

b School of Dentistry, University of Sao Paulo (USP), São Paulo, SP, Brazil
\end{abstract}

\author{
Correspondence: \\ Newton Fernando Sobreira Nóbrega \\ School of Medicine, Federal University of São Paulo \\ (UNIFESP) \\ Department of Image Diagnostics \\ Rua Itapura 129 - 141 \\ São Paulo, SP - Brazil \\ 03310-000
}

E-mail: newton.nobrega@superig.com.br

Received: January 24, 2012

Accepted: August 8, 2012

Conflict of Interests: The authors state that there are no financial and personal conflicts of interest that could have inappropriately influenced their work.

Copyright: (c) 2012 Nóbrega et al.; licensee EDIPUCRS. This is an Open Access article distributed under the terms of the Creative Commons AttributionNoncommercial-No Derivative Works 3.0 Unported License. 


\section{Introduction}

Radiology has undergone drastic changes in the last two decades, not only in hardware, but also in diagnostic imaging systems. Digital analysis systems and high definition images have widened the range of investigative options, among which Digital Radiography stands out in particular. Even though this imaging method is available on the market, its high cost still prevents it from being used in most dental clinics.

Before digital radiography, computerized resources could be applied only indirectly, in that conventional radiographs were captured through video cameras or appropriate scanners, and only then could they be manipulated using general or dental-specific software. Some authors have stressed the advantages of digital images (1).

Any radiographic image is composed of different shades of gray. Considering a numeric scale where each shade of gray is represented by a number (or grayscale level), the greater the number of levels representing a digital radiograph, the clearer the image will be. The number of gray levels of a given image is referred to as the image radiographic density. A digital image uses a two-dimensional system organized as numbers. The term "digital" originates from the way the computer processes the image. The digital image is the result of converting an analog signal into a digital signal (2).

There are three methods of digital radiography (3):

- Indirect method: a radiograph is scanned or filmed by a video camera, transferred to a computer screen, and then handled.

- Semi-direct method: a latent digital image is obtained by exposing a storage card (PSP - Phosphor Storage Plate) to radiation

- Direct method: a digital image is captured directly by an intraoral sensor, and then transferred to a computer through a cable. Once on the computer, the image can be manipulated, processed, stored, printed or transferred by telecommunications means to other locations, allowing concomitant assessment of the image by the several different parties involved.

Classification discrepancies may be found in the related literature. Some authors classify any system using phosphor plates as a direct method (4), which is in agreement with the criterion adopted in the present study.

Several digital radiographic systems have been released on the market, prompting surveys undertaken to assess their performance. Highly divergent results have been reported regarding the efficiency of the apparatuses and systems provided by various manufacturers. Several studies have found the image quality provided by charge-coupled device systems (CCD) $(5,6)$ to be equivalent to that provided by the Digora PSP system (7). Others have reported PSP images as being superior to film or CCD images $(8,9)$. Yet other authors have reported conventional film images as displaying better diagnostic performance, compared to digital systems (10).
Some digital imaging software that is not specific to dentistry or that is not designed to be used together with dental digital radiographic equipment is typically available on the market at a relatively affordable cost, whereas software specific to dental digital radiographic systems may be quite expensive.

The digital and conventional systems used to analyze the gray levels of biomaterials have been assessed for their accuracy and reproducibility (11-16). However, divergent results found in the related literature regarding these digital radiographic systems warrant the further investigation of imaging software options and acquisition methods (4,5,7-10).

The purpose of this study was thus to compare the radiographic gray levels of selected biomaterials images obtained with the direct and the indirect methods. The reproducibility between methods was also evaluated.

\section{Methodology}

Initially, test specimens were made with the following biomaterials: zinc phosphate cement, composite resin, glass ionomer cement, calcium hydroxide, gutta percha, and zinc oxide and eugenol paste. All these biomaterials were handled according to the instructions provided by their respective manufacturers. All test specimens were measured with digital calipers to certify a diameter of $8 \mathrm{~mm}$ and a thickness of $2 \mathrm{~mm}$.

The specimens were then radiographed using the indirect and direct methods (Fig. 1A and 1B). Size 2 Kodak $^{\circledR}$ E Speed Dental Films (Eastman Kodak, Rochester, NY, USA) were used in the indirect method (digitized radiography), together with a Timex 70 Gnatus ${ }^{\circledR}$ X-ray machine (Gnatus, Ribeirão Preto, SP, Brazil), set to operate at $70 \mathrm{kV}$ and $8 \mathrm{~mA}$, with an additional aluminum filter of $1.0 \mathrm{~mm}$, total aluminum filtration of $3.81 \mathrm{~mm}$, and a $30-\mathrm{cm}$ film-to-target distance. The exposure times ranged from 0.1 to 1.5 seconds, with 0.1 second increments, as well as exposure times of 2.0 and 2.5 seconds, for a total of 17 different exposure times.

Chemical processing was performed after exposure with the AT2000 ${ }^{\circledR}$ automatic film processor (Air Tecnhiques Inc., Melville, NY, USA). The temperature was standardized at $29^{\circ} \mathrm{C}$, and a processing time of 4 minutes and 30 seconds (dry to dry) was used, applying fresh Kodak ${ }^{\circledR}$ Readmatic solutions (Eastman Kodak, Rochester, NY, USA), mixed according to the manufacturer's instructions.

The radiographs were digitized (Fig. 1C) with an Express A3 USB ION ${ }^{\circledR}$ scanner, (ION Indústria, Belo Horizonte, MG, Brazil) aided by Scan Express ${ }^{\circledR}$ software (ION Indústria, Belo Horizonte, MG, Brazil). The digitized images were then imported into the Adobe Photoshop CS2 software (Adobe Systems Inc., San Jose, CA, USA) in JPEG format, with 300 dpi resolution, 1:1 compression (i.e., 100\% of its original size) and without any changes in its original density. A black mask was used to minimize the influence of diffuse light around the set of scanned radiographs. 

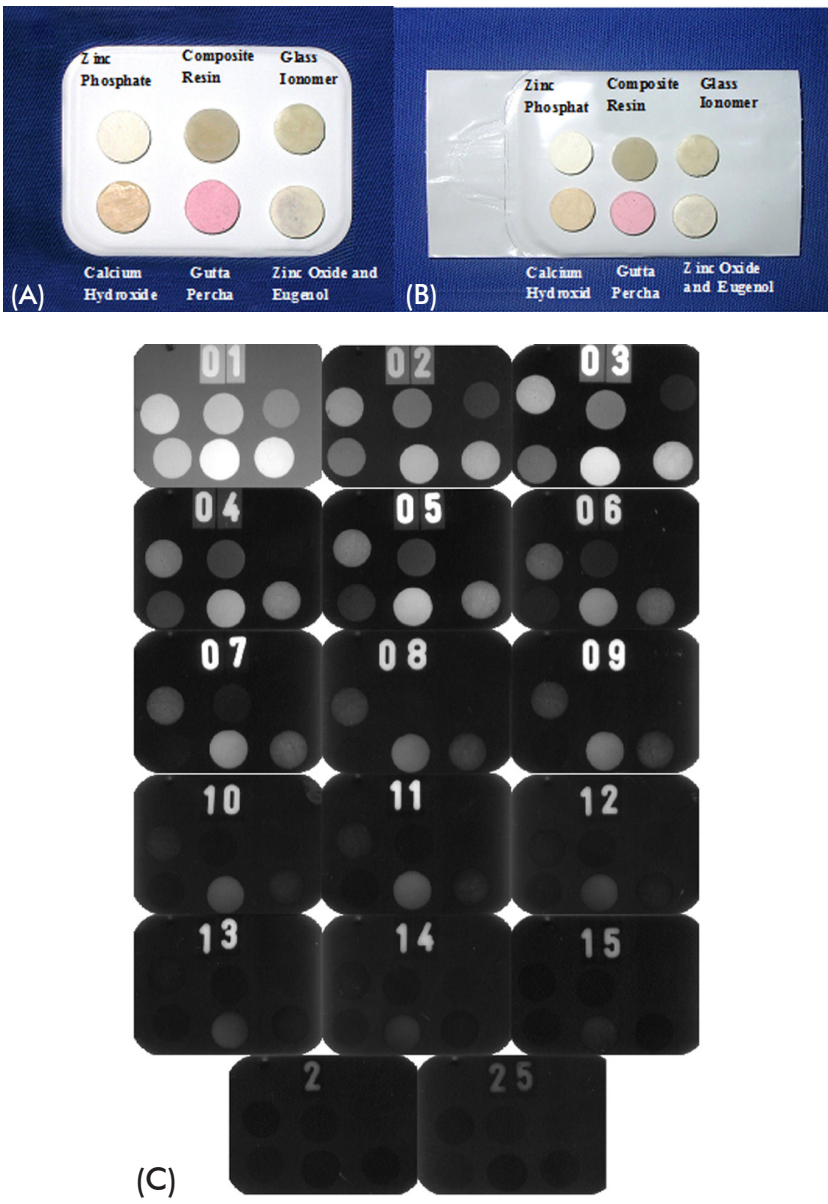

Fig. 1. Distribution of test specimens on conventional radiographic film $(A)$, distribution of test specimens on the phosphor plate (B), and digitized periapical radiographs (C).

The Digora $^{\circledR}$ system (Soredex Orion Corporation, Helsinki, Finland) was used in the direct method (digital radiography). The specimens were radiographed using the same protocol of X-ray exposure mentioned above. The PSPs were used with their original plastic envelopes in order to protect the plates from brightness and humidity, as directed by the manufacturer. After exposure, the PSPs were immediately scanned by Digora ${ }^{\circledR}$.

An extender was used to standardize the film-to-target distance and keep the central X-ray beam at a $90^{\circ}$ angle to the radiographic film and the PSP (Fig. 2).

The gray level readings were made by Digora for Windows $^{\circledR}$ (Soredex Orion Corporation, Helsinki, Finland) and Adobe Photoshop CS2 ${ }^{\circledR}$ (Adobe Systems Incorporated, California, USA) software. The "histogram" tool was used to show the distribution of grayscale values within the demarcated region of interest (ROI). Each shade of gray may assume a value ranging from 0 to 255 , with 0 representing black (minimum density) and 255 representing white (maximum density). The ROI had a $25 \mathrm{~mm}^{2}$ area, and the mouse cursor was positioned $2 \mathrm{~mm}$ from the edge of each specimen (Fig. 3).
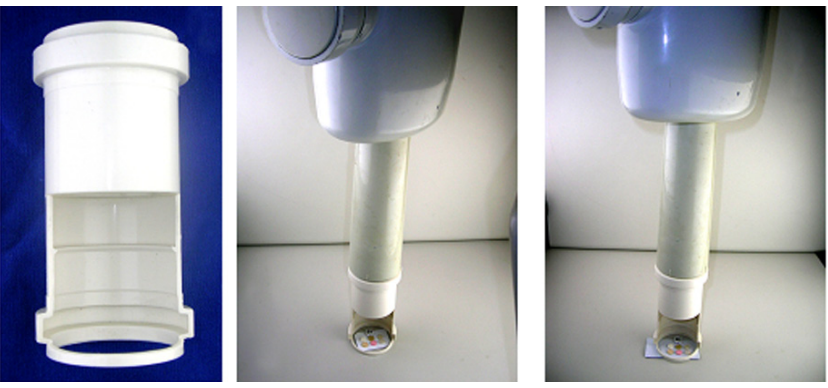

Fig. 2. Standardization of study methods: extender (A), image acquisition with conventional film (B) and with phosphor plate (C)

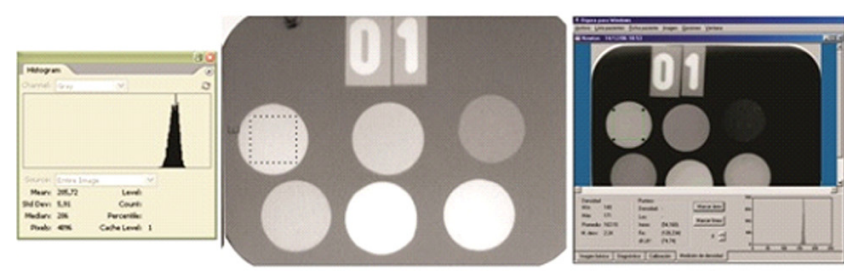

Fig. 3. Example of an area selected on the zinc phosphate cement test specimen to measure the grayscale level using Adobe Photoshop CS2 and Digora for Windows software on the left and on the right of the radiograph, respectively. Measurements of all test specimens were made using 17 different exposure times.

Two-way analysis of variance (ANOVA) was applied to assess the grayscale level differences between the direct and indirect evaluation methods. The correlation coefficient (ICC) was used to compare the methods and determine the reproducibility between them. Reproducibility was considered excellent when ICC $\geq 0.75$, satisfactory when $0.4 \leq \mathrm{ICC}<0.75$, and poor when ICC $<0.4$. A significance level of $5 \%$ was adopted throughout the analyses, i.e. p-values less than $0.05(P<0.05)$ were considered as representing significant results.

\section{Results}

The data shown in Figure 4 indicate that the measurements made using the direct method (Digora for Windows) were far more uniform overall than those made using the indirect method (Adobe Photoshop CS2).

This difference between the behavior of the two methods was statistically significant $(P<0.001)$, as confirmed by the ANOVA.

Table 1 and Figure 5 show that the ICC was greater than 0.75 only for the 0.2 and 0.3 second exposure times, demonstrating an excellent correlation between the direct and indirect methods. It was also noted that the level of significance of the test was very close to $5 \%$ for the 0.4 and 0.5 second exposure times, demonstrating a satisfactory correlation. The ICC was lower than 0.3 for all other exposure times, indicating a poor correlation. 


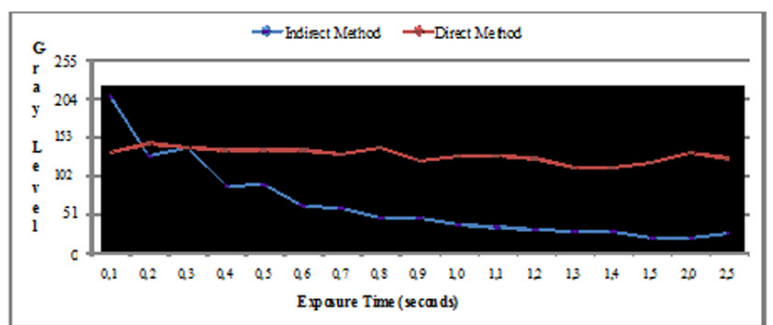

Fig. 4. Mean grayscale level values for the direct and indirect methods, according to exposure time.

Table 1. Estimates of the interclass correlation coefficient (ICC) according to exposure time and descriptive level of the test (P-value).

\begin{tabular}{ccc}
\hline Exposure time $(\mathrm{s})$ & ICC & $P$-value \\
\hline 0.1 & 0.1473 & 0.3600 \\
0.2 & 0.8556 & 0.0037 \\
0.3 & 0.9110 & 0.0009 \\
0.4 & 0.5921 & 0.0638 \\
0.5 & 0.5976 & 0.0617 \\
0.6 & 0.1613 & 0.3480 \\
0.7 & 0.2060 & 0.3106 \\
0.8 & -0.2341 & 0.6914 \\
0.9 & -0.0153 & 0.5031 \\
1.0 & -0.3736 & 0.7967 \\
1.1 & -0.3578 & 0.7856 \\
1.2 & -0.4638 & 0.8550 \\
1.3 & -0.4842 & 0.8669 \\
1.4 & -0.5029 & 0.8774 \\
1.5 & -0.7105 & 0.9648 \\
2.0 & -0.7270 & 0.9694 \\
2.5 & -0.6960 & 0.9605
\end{tabular}

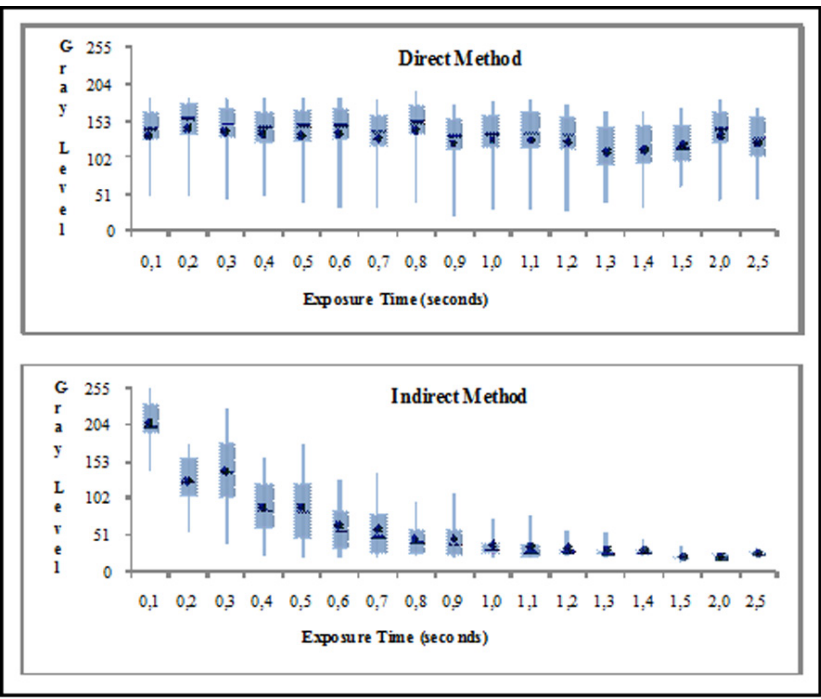

Fig. 5. Mean (SD) measurements of the gray levels obtained using the direct and indirect methods, according to exposure time.

\section{Discussion}

It was not the objective of our study to test the validity of the Digora program, since it has been used repeatedly for the purpose of examining the gray levels of biomaterials and bony segments in humans (10,13-15). The Digora digital radiography system is capable of measuring the optical density of pixels with a sufficient degree of sensitivity to detect small differences unnoticeable to the human eye (16). Related literature has also validated Adobe Photoshop software for the same purpose, and, in some cases, has shown a linear correlation between conventional film and the Digora system in assessing the density of biomaterials $(9,11,13-17)$. The images in the present study were stored in JPEG format, one of the most popular image formats owing to its ability to represent images faithfully.

Digital imaging programs, whether specific or nonspecific to digital radiology systems, usually include a histogram drawing tool, as well as tools for adjusting brightness and contrast. Digital radiography systems occasionally fail to use the whole scale of available gray values effectively. The images taken with these systems can be excessively or insufficiently dense, and may also show excessive or insufficient contrast in certain areas. The minimum and maximum density values, as well as the shape of the histogram, indicate the potential benefit of brightness and contrast enhancement actions (18).

Studies have reported the optical densities of various materials used in different dental areas, thus allowing the professional to take advantage of these readings to provide more accurate diagnoses. Additionally, optical density readings may be used in the radiographic expert reports required by several dental health insurance providers (19). Digital radiographic systems generally outperform expert reports on conventional radiographs required by dental health insurance providers, since carriers require confirmation of the procedures and materials used, and treatments typically generate a relatively large quantity of images. With digital radiography, images can be transmitted by telecommunications means (6), thus reducing costs with postal services. In addition, sending digital radiographic images to the health insurance provider immediately after acquisition allows expediting healthcare payments to dentists.

Other advantages of direct systems include the possibility of easily storing and retrieving radiographic images by the dentist, thus readily providing him with background information during consults, and for the purpose of lawsuits. The legal value of radiographic film is unquestionable; however, with the development of appropriate information technology applied to digital or scanned image acquisition, the absolute value of conventional film has become the object of judicial debate (20). When conventional radiographs are sent to the health insurance provider, they typically do not return to the dentist for appropriate archiving.

The superiority of the Digora direct digital radiography system, in several respects, has been reported in the related 
literature (4,7-9). Nevertheless, most professionals still cannot afford this type of technology $(2,10,21)$.

Test specimens were radiographed using either the direct or indirect method at 17 different exposure times i.e. with exposure times ranging from 0.1 to 1.5 seconds and also at 2.0 and at 2.5 seconds - in order to assess the behavior of conventional radiographic film and that of the phosphor plate, according to exposure time. An additional objective was to determine the least amount of exposure time required to achieve optimum reproducibility so as to obtain radiographs with diagnostic quality, while observing the ALARA principle ("as low as reasonably achievable"). It should be borne in mind that the radiation dose delivered is directly related to the set exposure time, and that 0.4 seconds is adequate to produce conventional radiographic images of diagnostic value.

An ICC estimate was determined for each time separately to ascertain whether the gray level measured by the direct method was similar to that measured by the indirect method. The coefficient estimates closer to one (1) indicate that the measures were more reproducible, i.e., that the two different methods arrived at more similar measures of gray levels.

The coefficient estimates (Table 1) confirm that the two methods were significantly correlated only for the exposure times of 0.2 and 0.3 seconds; a satisfactory correlation was observed for the times of 0.4 and 0.5 seconds $(P$-values very close to 0.05 ).

\section{Conclusions}

Considering the methodology applied in this study and based on the results observed, the indirect radiographic method is a feasible alternative to the direct method for assessing gray levels of biomaterials, since a satisfactory reproducibility was observed for the exposure times ranging from 0.2 to 0.5 seconds.

\section{References}

1. Wenzel A, Larsen MJ, Fejerskov O. Detection of occlusal caries without cent 2012;6:1 15 22.

2. Versteeg CH, Sanderink GC, van Ginkel FC, van der Stelt PF. An evaluation of periapical radiography with charge-coupled device. Dentomaxillofac Radiol 1998;27:97-101.

3. Graziottin LFR, Costa NP, Silveira ID, Veeck EB. Measurement of the optical density of packable composites - comparison between direct and indirect digital systems. Pesqui Odontol Bras 2002;16:299-307.

4. Costa C, Davidowicz H, Ortolani-Faltin CLF, Saraceni CHC. Avaliação das densidades das estruturas dentárias obtidas de imagens digitalizadas, utilizando-se a escala de níveis de cinza. Rev Inst Ciênc Saúde 2003;21:317-22.

5. Salzedas $L M P$, Louzada MFQ, Oliveira Filho AB. Radiopacity of restorative materials using digital images. J Appl Oral Sci 2006;14:147-52.

6. Oliveira MJ. Avaliação da digitalização de tiras densitométricas analisadas por quatro programas de imagens quanto aos níveis de cinza [Tese] Campo Grande: Universidade Federal do Mato Grosso do Sul; 2009.

7. Ergüçü Z, Türkün LS, Önem E, Güneri P. Comparative radiopacity of six flowable resin composites. Oper Dent 2010;35:436-440.

8. Akcay I, Ilhan B, Dundar N. Comparison of conventional and digital radiography systems with regard to radiopacity of root canal filling materials. Int Endod J. 2012 Mar 28 (Epub ahead of print) doi:10.1111/j.1365-2591.2012.02026.x

9. Costa C, Ishikiryama CN, Armonia PL, Saraceni CHC, Varoli FP. Contribuição para o estudo densitométrico do tecido ósseo por meio de imagens digitalizadas. Rev Inst Ciênc Saúde 2004;22:129-33.

10. Wenzel A. Effect of image enhancement for detectability of bone lesions in digitized intraoral radiographs. Scan J Dent Res 1988;96:149-60.

11. Couto AHC, Ruschel G, Fontana EB, Costa NP. Análise dos níveis de cinza de pinos intrarradiculares de quartzo em radiografias digitalizadas utilizando filmes de diferentes sensibilidades. Rev Odonto Ciênc 2004;19:131-38.

12. Falcão AFP, Sarmento VA, Rubira IRF. Valor legal das imagens radiográficas digitais e digitalizadas. Rev Cir Med Biol 2003;2:263-68.

13. Van der Stelt PF. Better Imaging: the advantages of digital radiography. J Am Dent Assoc 2008;139 Suppl.7S-13S. 